\title{
Contrast-induced encephalopathy
}

\author{
Babalova L ${ }^{1}$, Ruzinak $\mathrm{R}^{1}$, Ballova $\mathrm{J}^{1}$, Sivak $\mathrm{S}^{1}$, Kantorova $E^{1}$, Kurca E ${ }^{1}$, Zelenak $\mathrm{K}^{2}$, Nosal V ${ }^{1}$ \\ Clinic of Neurology, Jessenius Faculty of Medicine in Martin, Comenius University in Bratislava, Slovakia. \\ vladimir.nosal@uniba.sk
}

\begin{abstract}
Contrast-induced encephalopathy $(\mathrm{CIE})$ is a rare complication of the intravascular application of a contrast agent. CIE can be manifested by headache, cortical blindness, consciousness disorders, seizures, or focal neurological deficit. Neurological symptoms are typically transient with temporary abnormal findings on a brain scan. Urgent neuroimaging is important to obtain the correct diagnosis, especially in cases that require an acute management and treatment. We present a case of $\mathrm{CIE}$ after a digital subtraction angiography of the vertebral arteries in the patient with a symptomatic pre-occlusive stenosis of the posterior cerebral artery (Ref. 36). Text in PDF www.elis.sk KEY WORDS: encephalopathy, iodixanol, contrast agent, cortical blindness, cerebral angiography.
\end{abstract}

\section{Introduction}

Intravascular application of iodinated contrast agents is sometimes associated with a relatively rare complication such as neurotoxicity. Iodinated contrast agents are classified based on: osmolality (high, low and iso-osmolar), ionicity (ionic, non-ionic) and number of benzene rings (monomers, dimers). Ionic contrast agents have been used for diagnostic purposes for many years. Intravascular application has been associated with many side effects (approximately in $15 \%$ ) attributable to their hyperosmolality compared to non-ionic contrast agents with a lower osmolality ( $3 \%)$. Nowadays, non-ionic agents are used for intravascular application (1).

Adverse reactions of the contrast agents are divided in to two basic types: idiosyncratic (probably mediated by the release of vasoactive substances such as: histamine, serotonin and complement activation) and non-idiosyncratic (caused by a direct toxicity that depends on the physical and chemical properties of contrast agent such as: ionic state, osmolality, and iodine concentration). Idiosyncratic (anaphylactoid) reactions typically manifest as: urticaria, pruritus, nausea, vomiting, angioedema, bronchospasm, laryngeal oedema, tachycardia, bradycardia, arrythmias, hypotension, pulmonary oedema, or death. Non-idiosyncratic (non-anaphylactoid) reactions include fever, nausea, vomiting, bradycardia, hypotension, vasovagal reactions, delayed reactions and contrast-induced nephropathy $(2,23)$.

${ }^{1}$ Clinic of Neurology, Jessenius Faculty of Medicine in Martin, Comenius University in Bratislava, Slovakia, and ${ }^{2}$ Clinic of Radiology, Jessenius Faculty of Medicine in Martin, Comenius University in Bratislava, Slovakia

Address for correspondence: V. Nosal, Clinic of Neurology, Jessenius Faculty of Medicine in Martin, Comenius University in Bratislava, Kollarova 2, SK-036 01 Martin, Slovakia.

Phone: + 421905764991
Whether contrast-induced encephalopathy is a dose-dependent reaction or occurs regardless of the dose is unclear $(23,25)$.

\section{Case report}

A patient was 57-year-old man with a medical history of arterial hypertension, ischaemic stroke and diabetes type 2, who was admitted for the planned endovascular treatment of pre-occlusive posterior cerebral artery stenosis revealed by a computed tomography angiography.

The clinical picture at the admission showed only a slight reflex asymmetry and a mild cognitive deficit. Initial laboratory findings (parameters of liver and kidney function, electrolytes, C-reactive protein, blood glucose, blood cell counts and coagulation) were normal and his blood pressure was $155 / 80 \mathrm{mmHg}$.

The procedure was performed transfemorally. Initial intraarterial heparin was administered as a 4000 IU bolus followed by continual heparinization. Nimodipine was administered simultaneously. The patient received $400 \mathrm{ml}$ iodixanol (Visipaque 320, $290 \mathrm{mOsm} / \mathrm{kg} \mathrm{H}_{2} \mathrm{O}$ - non-ionic iso-osmolar dimer). An angiogram confirmed the presence of a pre-occlusive stenosis of the right posterior cerebral artery. Pre-dilation was performed prior to the stent placement (Wingspan $4.5 \times 20 \mathrm{~mm}$ ). The further angiogram revealed a residual stenosis after the stent had been positioned; the patient received a bolus of eptifibatide following by a continuous eptifibatide infusion. The final angiogram of the vertebrobasilar circulation was normal, without signs of distal emboli, residual stenosis, vasospasm, or dissection.

Directly after awakening from the anaesthesia, the patient noted a bilateral vision loss. Neurological examination revealed a bilateral blindness, oculomotor dysfunction (horizontal torsional nystagmus) and deviation of the eyes to the right. An immediately performed MRI (T1 weighted, T2 weighted, fluid-attenuated inversion recovery, diffusion weighted imaging and gradient echo 
sequences) of the brain showed no acute pathological findings. The three-dimensional time-of-flight MR angiogram visualised normal blood flow with no re-stenosis or in-stent thrombosis.

Five hours after the end of the procedure, the patient experienced nausea, vomiting, fever (above $38^{\circ} \mathrm{C}$ ) and epistaxis requiring a nasal tamponade. On the following day, the patient developed a qualitative and quantitative consciousness disorder (disorientation and somnolence, Glasgow Coma Scale 12 points). Laboratory parameters showed an increased white blood cell count (varying per day between values $10.2-12.7 \times 10^{9} / 1$ ); the concentration of $\mathrm{C}$-reactive protein was normal.

On the third day after the intervention, the patient's neurological condition began to improve rapidly and, by 6 days after the procedure, the symptoms had completely vanished. The patient was treated with intravenous mannitol, antibiotics, and antipyretics. Control MRI of the brain on day 20 was without changes compared to the initial MRI.

\section{Discussion}

CIE has a variable presentation and is usually temporary and reversible. A wide spectrum of clinical symptoms is known, including focal neurological deficits, seizures, transient cortical blindness, transient global amnesia, disturbances of consciousness and even death $(4-7,24)$. Transient vision impairment was first described in 1952 after a cerebral angiography with diodrast (2-(3,5-diiodo-4-oxopyridin-1-yl) acetate or iodopyracet), an ionic monomer (8). Several case reports describing similar symptoms after the application of iodinated contrast agents have subsequently been published (10-14).

The retrospective study of Yang et al (15) revealed that the analysed patients, who had undergone cerebral angiography (with ioversol) reported a vision impairment in $0.24 \%$ of the cases. A complete vision loss was experienced by $36.37 \%$ of the patients with a vision disorder. Transient cortical blindness was reported as the most frequent manifestation of CIE. The highest incidence was observed after an endovascular treatment of posterior circulation aneurysms (2.9\%) (9).

\section{Risk factors}

The multicentric study of Li et al (16) compared a group of patients, who developed cortical blindness after cerebral angiography (by ioversol) with the control group of patients, who underwent cerebral angiography without complications. The injection of a larger dose of contrast agent and administration directly to posterior circulation were observed as risk factors. Other authors reported a history of arterial hypertension, kidney disorders or diabetes, all of which are diseases leading to microangiopathy and affecting contrast agent elimination, as risk factors (25-27).

\section{Radiological findings}

Urgently performed CT of the brain in the patients, who developed CIE typically identified hyperdense areas, particularly in the subarachnoid space. Cerebral oedema was observed in some cases. These radiological findings together with clinical signs of neurological disorder subside within few hours to days $(5,7,11$, $14,16,17,18,20,21,34-36)$. The study of multiple cases of cortical blindness after a cerebral angiography with non-ionic iodinated contrast agents has reported the presence of MRI hyperintensities in the parietooccipital region (19). Other case reports described similar MRI findings in the patients with CIE, although the CT images were normal $(4,12)$. Cortical blindness after cerebral angiography with iodixanol and normal MRI findings is isolated (22). CIE after coronary angiogram by non-ionic contrast agents with normal CT and MRI findings is also rare (3, 27, 30-33).

\section{Pathophysiology of contrast agent's neurotoxicity}

Torvik and Walday (29) studied the neurotoxicity of contrast agents. They assume that, after intra-arterial application, ionic contrast agents can disrupt the blood-brain barrier (BBB) with subsequent leakage of the agent into the brain tissue because of hyperosmolality and a direct toxic effect on the vascular endothelium. Non-ionic contrast agents (including iodixanol) are also able to damage BBB, despite their low osmolality. Nikita et al (28) studied the effect of iodixanol by using an in vitro model for investigating brain vessel autoregulation. The hypothesis that contrast agents affect vessel tone has not been confirmed.

\section{Therapy}

No specific therapeutic strategy exists for CIE. Hydration and symptomatic therapy such as: anticonvulsant and antipyretic treatment under observation are recommended. Mannitol and corticosteroids have been applied in some cases. Symptoms and CT/ MRI findings resolve spontaneously without the need for specific treatment. Prognosis is excellent and permanent damage rarely occurs $(9,24)$.

\section{Conclusion}

Contrast-induced encephalopathy is an uncommon complication of cerebral as well as coronary and peripheral angiography. We described here the first known case of the patient with CIE in Slovak Republic. A brain scan and even MRI performed after the onset of symptoms can be normal. Even though the specific treatment is not known, the prognosis is excellent.

\section{References}

1. Pasternak JJ, Williamson EE. Clinical pharmacology, uses, and adverse reactions of iodinated contrast agents: a primer for the non-radiologist. Mayo Clin Proc 2012; 87 (4): 390-402.

2. Singh J, Daftary A. Iodinated contrast media and their adverse reactions. J Nucl Med Technol 2008; 36 (2): 69-77.

3. Dattani A, Au L, Tay KH, Davey P. Contrast-Induced Encephalopathy following Coronary Angiography with No Radiological Features: A Case Report and Literature Review. Cardiology 2018; 139 (3): 197-201.

4. Liao MT, Lin TT, Lin LY, Hwang JJ, Tseng CD. Contrast-Induced Encephalopathy after Percutaneous Coronary Intervention. Acta Cardiol Sin 2013; 29 (3): 277-280. 
$618-620$

5. Heemelaar JC, van der Hoeven NW, Muller FF, Appelman Y. Acuteonset coma after iso-osmolar iodinated contrast injection: a case report of contrast-induced encephalopathy after elective coronary angiography. Eur Heart J Case Rep 2018; 2 (4): yty132.

6. Shen NN, Wang JL, Wang J, Gu ZC. Transient Global Amnesia Induced by Iodixanol During Percutaneous Coronary Intervention: A Rare Neurological Adverse Reaction. J Cardiol Catheter 2019; (1): 26-28.

7. Donepudi B, Trottier S. A Seizure and Hemiplegia following Contrast Exposure: Understanding Contrast-induced Encephalopathy. Case Rep Med 2018; 2018: 9278526.

8. Walsh FB, Smith GW. The ocular complications of carotid angiography; the ocular signs of thrombosis of the internal carotid artery. J Neurosurg 1952; 9 (5): 517-537.

9. Leong S, Fanning NF. Persistent neurological deficit from iodinated contrast encephalopathy following intracranial aneurysm coiling. A case report and review of the literature. Interv Neuroradiol 2012; 18 (1): 33-41.

10. Silverman SM, Bergman PS, Bender MB. The Dynamics of Transient Cerebral Blindness: Report of Nine Episodes Following Vertebral Angiography. Arch Neurol 1961; 4 (3): 333-348.

11. Roccatagliata L, Taveira-Lopes L, Rossignol MD, Biondi A. Cortical Blindness and Retrograde Amnesia Following Cerebral Angiography Studied by Early Diffusion Weighted MR imaging. A Case Report. Neuroradiol J 2009; 22 (5): 600-604.

12. Lo LW, Chan HF, Ma KF, Cheng LF, Chan TK. Transient cortical blindness following vertebral angiography: a case report. Neurointervention 2015; 10 (1): 39-42.

13. Chen CY, Chen CJ, Tseng YC. A Case Report of Transient Cortical Blindness after Angiography. Neurologist 2017; 22 (3): 82-84.

14. Weiss A, Den Hollander J, Pietsch U. Transient Cortical Blindness: a Rare Complication After Cerebral Digital Subtraction Angiography. SN Compr Clin Med 2019; 1: 567-570.

15. Yang Y, Zhang J, Li T. The potential risk factors of cortical visual impairment following cerebral angiography: a retrospective study. Ther Clin Risk Manag 2019; 15:1013-1017.

16. Li M, Liang H, Liu C et al. Risk Factors of Transient Cortical Blindness after Cerebral Angiography: A Multicenter Study. Front Neurol 2019; 10: 1005 .

17. Chisci E, Setacci F, de Donato G, Setacci C. A case of contrastinduced encephalopathy using iodixanol. J Endovasc Ther 2011; 18 (4): $540-544$.

18. Studdard WE, Davis DO, Young SW. Cortical blindness after cerebral angiography. Case report. J Neurosurg 1981; 54 (2): 240-244.

19. Saigal G, Bhatia R, Bhatia S, Wakhloo AK. MR findings of cortical blindness following cerebral angiography: is this entity related to posterior reversible leukoencephalopathy? AJNR Am J Neuroradiol 2004; 25 (2): 252-256.
20. Eleftheriou A, Rashid AS, Lundin F. Late Transient Contrast-induced Encephalopathy after Percutaneous Coronary Intervention. J Stroke Cerebrovasc Dis 2018; 27 (6): e104-e106.

21. Park JC, Ahn JH, Chang IB, Oh JK, Kim JH, Song JH. A Case of Unusual Presentation of Contrast-induced Encephalopathy after Cerebral Angiography Using Iodixanol. J Cerebrovasc Endovasc Neurosurg 2017; 19 (3): 184-188.

22. Baguma M, Younan N, London F, Ossemann M, Vandermeeren Y. Contrast-associated transient cortical blindness: three cases with MRI and electrophysiology findings. Acta Neurol Belg 2017; 117 (1): 195-199.

23. Zhang G, Wang H, Li T, Liu J, Zhao L, Sun MJ, Jian Y. The Role of Blood-Brain Barrier Damage in the Pathogenesis of Contrast-Induced Encephalopathy. Arch Gen Intern Med 2018; 2 (2): 34-40.

24. Zhao W, Zhang J, Song $Y$ et al. Irreversible fatal contrast-induced encephalopathy: a case report. BMC Neurol 2019; 19 (1): 46.

25. Tong X, Hu P, Hong $T$ et al. Transient Cortical Blindness Associated with Endovascular Procedures for Intracranial Aneurysms. World Neurosurg 2018; 119: 123-131.

26. Kocabay G, Karabay CY, Kalayci A et al. Contrast-induced neurotoxicity after coronary angiography. Herz 2014; 39 (4): 522-527.

27. Spina R, Simon N, Markus R, Muller DW, Kathir K. Recurrent contrast-induced encephalopathy following coronary angiography. Intern Med J 2017; 47 (2): 221-224.

28. Nikitina T, Zavaritskaya O, Semenyutin V, Persson PB, Patzak A, Sendeski M. Effects of iodinated contrast media in a novel model for cerebral vasospasm. Arq Neuropsiquiatr 2015; 73 (2): 125-131.

29. Torvik A, Walday P. Neurotoxicity of water-soluble contrast media. Acta Radiol Suppl 1995; 399: 221-229.

30. Ting F, Bhat A, Markus R, Ortega M, Ting S. Contrast-induced encephalopathy post-angiography. Internet J Neurol 2013; 6: 1-3.

31. Ozelsancak R, Erken E, Yildiz I, Giray S, Yildirim T, Micozkadioglu H. A very rare case of encephalopathy in a patient with end-stage renal disease: contrast agent, ioversol. Ren Fail 2010; 32 (9): 1128-1130.

32. Kwok BW, Lim TT. Cortical blindness following coronary angiography. Singapore Med J 2000; 41 (12): 604-605.

33. Terlecki M, Wojciechowska W, Rajzer M et al. Transient cortical blindness after coronary artery angiography. Postepy Kardiol Interwencyjnej 2013; 9 (1): 105-108.

34. Shinoda J, Ajimi Y, Yamada M, Onozuka S. Cortical blindness during coil embolization of an unruptured intracranial aneurysm - case report. Neurol Med Chir (Tokyo) 2004; 44 (8): 416-419.

35. Lim KK, Radford DJ. Transient cortical blindness related to coronary angiography and graft study. Med J Aust 2002; 177 (1): 43-44.

36. Balasingam S, Azman RR, Nazri M. Contrast media induced transient cortical blindness. QJM 2016; 109 (2): 121-122.

Received February 3, 2021. Accepted March 25, 2021. 